\title{
Tracheobronchoplasty outcomes: a narrative review
}

\author{
Jennifer L. Wilson ${ }^{1,2}$, James S. Wallace ${ }^{3}$ \\ ${ }^{1}$ Department of Surgery, Harvard Medical School, Boston, MA, USA; ${ }^{2}$ Department of Thoracic Surgery, Beth Israel Deaconess Medical Center, \\ Boston, MA, USA; ${ }^{3}$ Department of General Surgery, Beth Israel Deaconess Medical Center, Boston, MA, USA \\ Contributions: (I) Conception and design: Both authors; (II) Administrative support: None; (III) Provision of study materials or patients: None; (IV) \\ Collection and assembly of data: None; (V) Data analysis and interpretation: None; (VI) Manuscript writing: Both authors; (VII) Final approval of \\ manuscript: Both authors. \\ Correspondence to: Jennifer L. Wilson, MD, MPH, FACS. 185 Pilgrim Road, W/D 201, Boston, MA 02215, USA. Email: jwilso10@bidmc.harvard.edu.
}

Objective: Herein, we will summarize the most recent adult tracheobronchoplasty outcome data available. We hope this review will encourage others to report their outcome data and allow clinicians to design studies that capture previously reported outcome measures, so that novel and established therapies can be appropriately evaluated.

Background: Excessive central airway collapse (ECAC) consists of excessive dynamic airway collapse (EDAC) and severe tracheobronchomalacia (TBM), two aberrant pulmonary physiologies that refer to the inappropriate movement of the central airway. Typically, EDAC involves the abnormal movement of the posterior membrane, while TBM relates to changes in the cartilaginous portion of the trachea. All can cause debilitating respiratory symptoms. In general, these symptoms can mimic or overlap with common pulmonary diseases such as asthma and chronic obstructive pulmonary disease likely making diagnosis of ECAC underreported. Although screening protocols for ECAC are non-existent, once diagnosed, surgical intervention or tracheobronchoplasty can be offered to highly selected patients at centers with complex airway disease expertise. The preoperative evaluation of patients requires a multi-disciplinary approach. Comorbid conditions are then optimized, and patients with persistent symptoms that are surgical candidates often undergo a temporary stent trial over the course of 1-2 weeks to assess improvement of subjective and objective parameters. This process can help determine if a tracheobronchoplasty is likely to offer symptomatic relief. The scope of this review is to compile the recent data in severe adult TBM.

Methods: A narrative review through the PubMed (MEDLINE) database was performed using the keyword tracheobronchoplasty. Non-pediatric studies pertaining to perioperative, subjective, and objective outcomes after tracheobronchoplasty for severe symptomatic TBM in adults published between 2010-2020 were retained. Single patient case reports were excluded. Six publications from two institutions met inclusion criteria.

Conclusions: Almost half of the patients that undergo tracheobronchoplasty for severe symptomatic TBM will experience a perioperative complication (minor or major) regardless of operative approach. With appropriate patient selection, authors have demonstrated improvement of patient reported, objective, and functional outcomes. Current literature is limited to single center retrospective reviews from two institutions. More data can refine the current treatment paradigms and establish improved outcome metrics.

Keywords: Bronchomalacia; tracheobronchomalacia (TBM); tracheomalacia; patient reported outcome measures; postoperative complications

Received: 13 February 2021; Accepted: 26 July 2021; Published: 20 April 2022.

doi: 10.21037/jovs-21-10

View this article at: https://dx.doi.org/10.21037/jovs-21-10

^ ORCID: 0000-0001-8824-3952. 


\section{Introduction}

Excessive central airway collapse (ECAC) can cause a plethora of symptoms including a barking cough, shortness of breath, inability to clear secretions, and recurrent respiratory tract infections. Except in rare cases of extreme pulmonary collapse where patients are left gasping for air, ECAC typically represents a non-life-threatening quality of life (QOL) problem. Associated symptoms can mimic or overlap with commonly recognized diseases such as asthma and chronic obstructive pulmonary disease (COPD). The true prevalence of symptomatic ECAC (TBM) remains unknown, but it is almost certainly under-diagnosed as screening data is non-existent (1). The cause remains elusive, although it is associated with gastroesophageal reflux disease (GERD) $(2,3)$ and high dose inhaled corticosteroids (4). Over the past decade, interest in this disease has grown and is reflected in the increased number of publications available in recent literature. We aim to review the available literature regarding the outcomes of tracheobronchoplasty (TBP) for severe symptomatic TBM during the perioperative period and beyond.

Reviewing the available data is a challenge due to highly variable follow-up intervals and a broad array of metrics. In addition, patients that are lost to follow up, undoubtedly impedes long-term outcome reporting. Furthermore, there are no validated QOL measurement scales specific to TBM. Authors have reported QOL data using existing measurement scales that were designed and validated in common respiratory diseases such as asthma and COPD and served as a QOL surrogate in this population. Despite the similarities in clinical presentation, it is unclear if this is an accurate way to report QOL data for patients with TBM. We present the following article in accordance with the Narrative Review reporting checklist (available at https:// jovs.amegroups.com/article/view/10.21037/jovs-21-10/rc).

\section{Methods}

A narrative review through the PubMed (MEDLINE) database was performed using the keyword tracheobronchoplasty. Non-pediatric studies pertaining to perioperative, subjective, and/or objective outcomes after tracheobronchoplasty for severe symptomatic TBM in adults published from 2010-2020 were retained. Single patient case reports were excluded. Six publications from 2 institutions met inclusion criteria. These publications are limited to single center retrospective reviews from Lenox
Hill Hospital in New York, New York (1 publication) and Beth Israel Deaconess Medical Center in Boston, Massachusetts (5 publications).

\section{Results}

\section{Perioperative outcomes}

Tracheobronchoplasty is a complex and laborious procedure that requires appropriate patient selection, in-hospital resources, and a multidisciplinary care team approach. Generally speaking, post-operative outcomes are impacted by patient comorbidities and operative modalities. We will discuss the 2 most recent TBP perioperative outcome manuscripts in detail $(5,6)$ (Table 1). Both institutions stratified perioperative complications based on the ClavienDindo classification system (5). This classification grades the severity of complications in an objective and reproducible manner and delineates outcomes from $\mathrm{I}$ to $\mathrm{V}$ based on divergence from a normal postoperative course. ClavienDindo grade I describes any deviation from a normal postoperative course without the need of pharmacological treatment or surgical/endoscopic/radiologic interventions. A class IIIa complication is any problem that requires surgical/endoscopic/radiologic interventions that do not require anesthesia (7). Thirty- and 90-day outcomes have been reported by only 2 institutions over the past decade $(3,5,6)$. Both institutions report a significant incidence of perioperative complications (45-47\%) (Table 1). However, Lazzaro et al. reported outcomes on 42 patients that underwent a robotic TBP (rTBP) from 2016-2017 while Buitrago et al. reported outcomes of 161 patients that underwent an open TBP from 2002-2016 (5). Both authors further classified their complications as major (ClavienDindo $\geq$ IIIa) or minor (Clavien-Dindo < IIIa). The most common complications reported by these institutions were pulmonary in nature and included respiratory failure, respiratory infections, pneumothorax, and subcutaneous emphysema. To follow, we will discuss perioperative complications after TBP in more detail.

The largest series published resulted in a single center retrospective analysis of 161 patients that underwent TBP from October 2002 to September 2016 at BIDMC (5). The authors found that several preoperative factors were associated with an increased risk of postoperative complications in particular, age $(\mathrm{P}<0.001)$, coronary artery disease $(\mathrm{P}=0.003)$, COPD $(\mathrm{P}<0001)$, congestive heart failure $(\mathrm{P}=0.0003)$, diabetes mellitus 
Table 1 Perioperative outcomes after tracheobronchoplasty

\begin{tabular}{|c|c|c|c|c|c|c|c|}
\hline First author & Institution & $\begin{array}{l}\text { Operative } \\
\text { approach }\end{array}$ & $\begin{array}{l}\text { Inclusion } \\
\text { years }\end{array}$ & \# patients & $\begin{array}{l}\text { Overall perioperative } \\
\text { complications }\end{array}$ & $\begin{array}{c}\text { Minor } \\
\text { complications }^{\dagger}\end{array}$ & $\begin{array}{c}\text { Major } \\
\text { complications }^{\dagger}\end{array}$ \\
\hline Buitrago (5) & BIDMC & Thoracotomy & 2002-2016 & 161 & $75 / 161(47 \%)$ & $37 / 161$ (23\%) & $38 / 161(24 \%)$ \\
\hline Lazzarro (6) & LHH & Robotic & 2016-2017 & 42 & 19/42 (45\%) & $11 / 42$ (26\%) & $8 / 42(19 \%)$ \\
\hline
\end{tabular}

${ }^{\dagger}$, minor complications classified as Clavien-Dindo < IIla and major complications classified as Clavien-Dindo $\geq$ IIla. BIDMC, Beth Israel

Deaconess Medical Center (Boston, Massachusetts); LHH, Lenox Hill Hospital (New York, New York).

( $\mathrm{P}=0.011)$, continuous home oxygen requirement $(\mathrm{P}<0.001)$, and recent treatment $(<90)$ of pneumonia $(\mathrm{P}=0.014)$. Baseline functional factors that contributed to postoperative complications were impaired pulmonary function tests (FEV1, FVC; $\mathrm{P}<0.0001$ ), and diffusion capacity (DLCO; $\mathrm{P}<0.001)$. The study results showed that $47 \%$ of patients (75 of 161) experienced a post-operative complication while approximately $50 \%$ of patients with complications were classified as severe (Clavien-Dindo $>$ IIIa). The nonsevere (< IIIa) complications (23\%) included postoperative respiratory infections, acute kidney injury, recurrent pleural effusion, pneumothorax, atrial arrhythmias, urinary tract infections, and wound infections. The severe complications identified were postoperative bleeding, mesh erosion, acute chest wall hernia, rhabdomyolysis, acute kidney injury requiring HD, and sepsis. The 30-day mortality in this series was $1.2 \%$, with most patients (69\%) abled to be discharged home or home with VNA by day 8 . Although limited to 30 days, this study provides a safety assessment that can help improve perioperative management in future studies.

In addition, Lazzaro et al. at Lenox Hill were able to provide compelling data on the benefits of robotic tracheobronchoplasty as well create a risk profile using the Clavien-Dindo classification (6). They presented data from a cohort of 42 patients that underwent robotic tracheobronchoplasty with comorbidities similar to the BIDMC group. Many patients had asthma (88\%), COPD (52\%), GERD (85\%), hypertension (52\%), diabetes mellitus (26\%), and cardiovascular disease (14\%). Using the Clavien-Dindo classification, Lazzaro et al. had a total of 19 postoperative complications, with 8 patients having severe complications (19\%). The minor complications were an asymptomatic pneumothorax, self-resolving subcutaneous emphysema, pneumonia, and bronchitis. Their ClavienDindo classification IIIa and above complications included hemothorax evacuation, pneumothorax and subcutaneous emphysema requiring decompression, a return to ICU for bronchoscopy and arrhythmia, and a takeback for revision at postoperative day 125 . This group evaluated these complications at a 90-day benchmark and had no reintubations, tracheostomies or mortalities.

In summary, almost half of patients undergoing TBP experience a complication in the perioperative period. The top 3 complications observed in the open cohort from BIDMC were respiratory failure (17\%), respiratory infection requiring antibiotics (18\%), and acute renal failure (11\%) (5). The top 3 complications in the rTBP cohort from Lenox Hill were respiratory infection requiring antibiotics (16.7\%), pneumothorax or subcutaneous emphysema requiring no intervention $(9.5 \%)$, and pneumothorax or subcutaneous emphysema requiring intervention (9.5\%) (6). Future technological advancements and improvement in operative performance may bridge the gap between a complex surgery and good outcomes.

\section{Patient-reported outcomes}

\section{How do we define 'success' when we are treating a QOL problem with no validated QOL measurement tool?}

While TBM remains a non-life-threatening airway disease that impacts QOL, existing QOL measurement scales have never been validated in patients with TBM. This remains an area of interest and ongoing research at BIDMC. As evident in Table 2, different QOL scales have been employed in this population including the Modified Medical Research Council Dyspnea Scale (mMRC), Cough Specific Quality of Life Scale (CSQOL), St. George's Respiratory Questionnaire (SGRQ), American Thoracic Society (ATS) dyspnea scale (3,6,8-10). In addition, the Karnofsky Performance Scale has been used as a selfreported functional impairment metric.

\section{Short term self-reported outcomes}

Lazzaro et al. reported improvement in SGRQ over a median of 2 months (IQR 1-4 months) of follow up in 15 patients (6). Majid et al. showed an improvement in 
Table 2 Patient reported outcomes after tracheobronchoplasty

\begin{tabular}{|c|c|c|c|c|c|c|}
\hline First author & Institution & $\begin{array}{l}\text { Inclusion } \\
\text { years }\end{array}$ & \# patients & $\begin{array}{l}\text { Average or median } \\
\text { follow up (range) }\end{array}$ & Improvement of symptoms & $\begin{array}{l}\text { Patient-reported } \\
\text { scale demonstrating } \\
\text { improvement }\end{array}$ \\
\hline Bezuidenhout (8) & & & & 6 years & Overall: 11/17 (65\%) & - \\
\hline Ernst (9) & BIDMC & 2002-2009 & 21 & - & - & $\begin{array}{l}\text { SGRQ, ATS } \\
\text { dyspnea scale, KPS }\end{array}$ \\
\hline Gangadharan (3) & BIDMC & 2002-2009 & 33 & - & - & $\begin{array}{l}\text { SGRQ, ATS } \\
\text { dyspnea scale, KPS }\end{array}$ \\
\hline \multirow[t]{2}{*}{ Lazzaro (6) } & LHH & 2016-2017 & 33 & 13 months (8 to 15.5$)$ & $\begin{array}{l}\text { Improved: cough } 24 / 33(72 \%) \text {, } \\
\text { SOB } 19 / 33(57 \%) \text {, respiratory } \\
\text { infections } 17 / 25(68 \%) \text {, ability } \\
\text { to 'move air' } 25 / 35(71 \%) \text {; } \\
\text { satisfaction with the overall results } \\
\text { of the procedure: } 29 / 35(82 \%)\end{array}$ & - \\
\hline & & & 15 & 2 months ( 1 to 4 ) & - & SGRQ \\
\hline Majid (10) & BIDMC & 2013-2015 & 13 & 3 months & $\begin{array}{l}\text { Improved: dyspnea } 10 / 13(77 \%) \text {, } \\
\text { cough } 11 / 13(85 \%) \text {, secretions } \\
5 / 6(83 \%)\end{array}$ & $\mathrm{mMRC}$ and CQLQ \\
\hline
\end{tabular}

BIDMC, Beth Israel Deaconess Medical Center (Boston, Massachusetts); LHH, Lenox Hill Hospital (New York, New York). HRQOL, health related quality of life; SOB, shortness of breath; SGRQ, St. George Respiratory Questionnaire; mMRC, modified Medical Research Council; CQLQ, Cough Quality of Life Questionnaire; ATS, American Thoracic Society; KPS, Karnofsky Performance Scale.

the mMRC and CSQOL scales at a mean 3 months of follow up in 13 patients (10). In addition, 11/13 (77\%) reported improved dyspnea and 11/13 reported improved cough, 5/6 (83.3\%) reported improved ability to clear secretions (10). Gangadharan et al. showed an improvement in the Karnofsky performance scale, ATS dyspnea score, and SGRQ quality of life questionnaire (all $\mathrm{P}>0.001$ ) (3).

\section{Intermediate and longer-term self-reported outcomes}

Lazzaro et al. noted improvement in self-reported symptoms over a median follow up of 13 months (IQR 8-15.5 months) including cough (24/33, 72\%), shortness of breath $(19 / 33,57 \%)$, ability to manage respiratory infections $(17 / 25,68 \%)$, ability to "move air" while breathing $(25 / 35,71 \%)$, and overall satisfaction with the results (29/35, 82\%) (6). Bezuidenhout et al. reported the intermediate outcomes of 17 patients followed for a mean of 1.5 years and showed that $14 / 17$ (82.3\%) had selfreported improvement of symptoms (8). This improvement decreased to $11 / 17(64.7 \%)$ at a longer term follow up of 6 years (8).

\section{Objective outcomes}

While ECAC (TBM) mainly affects the quality of life, finding objective measures to collect that can track the success, failure, durability, and other desired outcome metrics have proven challenging. Several authors have noted that TBM and TBP do not correlate with changes in pulmonary function testing and therefore we will not review these outcomes in this review. We have summarized the most recent literature available in Table 3. Interestingly, Lazzaro et al. demonstrated statistically significant improvement in median predicted FEV1 $(62.5 \%$ to $76 \%$; $\mathrm{P}=0.01)$, median predicted FVC $(69.5 \%$ to $84 \%$; $\mathrm{P}<0.0001)$, and median predicted peak expiratory flow $(60 \%$ to $81 \%$; $\mathrm{P}<0.001)$ after $\mathrm{rTBP}$. It is unclear if the primary driver is the robotic approach or patient selection, however, finding objective improvement is applauded (6).

\section{The 6-minute walk test (6MWT)}

Pulmonary function tests are obvious test measures for respiratory diseases, however the forced expiratory volume 
Table 3 Objective outcomes after tracheobronchoplasty

\begin{tabular}{|c|c|c|c|c|c|c|c|}
\hline First author & Institution & $\begin{array}{l}\text { Operative } \\
\text { approach }\end{array}$ & $\begin{array}{l}\text { Inclusion } \\
\text { years }\end{array}$ & \# patients & $\begin{array}{l}\text { Mean } \\
\text { follow up }\end{array}$ & $\begin{array}{l}6 \mathrm{MWT} \\
\text { improvement }\end{array}$ & $\begin{array}{l}\text { Mean anatomic improvement in } \\
\text { percentage collapse on surveillance } \\
\text { dynamic airway CT }\end{array}$ \\
\hline \multirow{2}{*}{ Bezuidenhout (8) } & \multirow{2}{*}{ BIDMC } & \multirow{2}{*}{ Thoracotomy } & \multirow{2}{*}{ 2003-2016 } & \multirow{2}{*}{18} & 1.5 years & 50 meters $( \pm 98)^{\dagger}$ & Lower trachea: $33 \%( \pm 19)$ \\
\hline & & & & & 6 years & $\begin{array}{l}20 \text { meters }^{+} \\
( \pm 131)^{\dagger}\end{array}$ & Upper trachea: $21 \%( \pm 20)$ \\
\hline Lazzaro (6) & $\mathrm{LHH}$ & Robotic & 2016-2017 & 17 & 5 months & 1.8 meters & - \\
\hline
\end{tabular}

${ }^{\dagger}$, this outcome was reported for 11 patients. BIDMC, Beth Israel Deaconess Medical Center (Boston, Massachusetts); LHH, Lenox Hill Hospital (New York, New York); CT, computed tomography; 6MWT, 6-minute walk test.

in 1 second (FEV1) does not correlate with the extent of TBM or TBP outcomes $(3,11)$. However, using the $6 \mathrm{MWT}$ as a functional surrogate to document improvement in the distance walked after surgery has been described. Bezuidenhout et al. showed an increase in the distance walked by an average of 50 meters in the intermediate term (1.5 years) in 11 patients (8). This improvement decreased to 20 meters over a 6 -year follow up in the same patient cohort (8). Gangadharan et al. reported an increase of 60 meters on average in a series of 63 patients (3). Lazzaro reported an increase in the distance walked by 1.83 meters over a median follow up of 5 months in 11 patients after rTBP (6). The reason for significant difference in the change in $6 \mathrm{MWT}$ between operative approaches remains unclear.

\section{Dynamic airway CT and bronchoscopy findings}

TBM can be defined with dynamic expiratory CT imaging or dynamic bronchoscopy when there is a $>70 \%$ reduction in the tracheal luminal cross-sectional area. However, an intervention is typically only considered if the reduction reaches $\geq 80-90 \%(3,6,8)$. A helical CT performed in the craniocaudal dimension can be used to analyze and document this change in the central airway infrastructure. To calculate the percentage of luminal collapse, the crosssectional area of the airway lumen is measured on endinspiratory and dynamic expiratory scans by tracing the inner wall of the airway with an electronic tracing tool at standard levels $(8,12,13)$. Although dynamic airway CT is highly sensitive in evaluating severe airway collapse at centers that perform frequent dynamic airway CT scans, deficient coaching or suboptimal respiratory effort during the exam can produce inaccurate results (14).

Monitoring the durability of TBP postoperatively with serial dynamic airway CT scans and/or dynamic bronchoscopy has also been described (8). Bezuidenhout et al. were the first to report intermediate (1.5 years) and long term (6 years) clinical and radiographic outcomes in patients that underwent TBP at BIDMC (8). The authors showed that post-operative clinical outcomes correlated with CT findings and degree of recurrent collapsibility after TBP. Over time, patients symptoms remained improved over baseline, but decreased in the long term with reported improvement going from $82 \%$ to $65 \%$. In addition, 11 of the patients had serial $6 \mathrm{MWT}$ Terformed and this showed an increase in the distance walked at 1.5 years of an average of 50 meters $( \pm 99 \mathrm{~m})$. This decreased to 20 meters $( \pm 131 \mathrm{~m})$ in the long term. These findings suggest that radiographic dynamic airway collapse does correlate with symptom recurrence.

\section{Limitations}

This review is limited by the paucity of existing and retrospective data that reflect the experience of 2 single centers. Therefore, outcomes are subject to selection bias and outcomes may not be generalizable.

\section{Conclusions}

TBP remains an arduous procedure that is associated with a significant rate of perioperative complications. It is clear that subjective and objective outcome measures improve after TBP in highly selected patients at centers with expertise in TBM. However, outcome reporting after 
TBP remains a challenge for several reasons. First, very few centers routinely treat patients with ECAC and are able to follow patients longitudinally. Second, physiological and anatomic assessments provide significant, but limited information of the impact of the disease process on a patient's life and sequalae of central airway stabilization. Specifically, there are no current QOL measurement tools that have been specifically validated in patients with TBM and therefore it is unclear if the scales that have been employed are the best way to capture meaningful patient reported outcome data.

Furthermore, until recently, TBP related outcomes have been published by only 1 center (BIDMC). We are very excited that the team at Lenox Hill Hospital has contributed to the literature and we would invite those performing TBP nationally to also collect and report their data so that we no longer reside in an academic echo chamber. It is unclear how many surgeons or centers in the United States are treating patients with TBM. The paucity of literature from only 2 centers greatly limits our ability to collectively learn and improve patient care.

All of this taken together demonstrates a tremendous opportunity for improvement. Now is a perfect time to review current outcome metrics for TBP so that centers relatively new to treating TBM can track and report their results with the common aim of improving patient care. In order to improve upon the treatment of TBM, it is important that centers collect and track subjective and objective outcome measures so that patient care can be optimized in the future and newer developing treatment modalities can be compared to surgical TBP as the Gold standard. In the future, standardizing follow up protocols and outcome data reporting across institutions could facilitate meaningful advancements in the field.

\section{Acknowledgments}

The authors would like to thank Sidhu Gangadharan MD MHCM, Adnan Majid MD, and Mihir Parikh MD for their contribution to this work.

Funding: None.

\section{Footnote}

Provenance and Peer Review: This article was commissioned by the Guest Editors (Charles T. Bakhos and Abbas E. Abbas) for the series "Tracheobronchoplasty" published in Fournal of Visualized Surgery. The article has undergone external peer review.

Reporting Checklist: The authors have completed the Narrative Review reporting checklist. Available at https:// jovs.amegroups.com/article/view/10.21037/jovs-21-10/rc

Conflicts of Interest: Both authors have completed the ICMJE uniform disclosure form (available at https://jovs. amegroups.com/article/view/10.21037/jovs-21-10/coif). The series "Tracheobronchoplasty" was commissioned by the editorial office without any funding or sponsorship. The authors have no other conflicts of interest to declare.

Ethical Statement: The authors are accountable for all aspects of the work in ensuring that questions related to the accuracy or integrity of any part of the work are appropriately investigated and resolved.

Open Access Statement: This is an Open Access article distributed in accordance with the Creative Commons Attribution-NonCommercial-NoDerivs 4.0 International License (CC BY-NC-ND 4.0), which permits the noncommercial replication and distribution of the article with the strict proviso that no changes or edits are made and the original work is properly cited (including links to both the formal publication through the relevant DOI and the license). See: https://creativecommons.org/licenses/by-nc-nd/4.0/.

\section{References}

1. Abia-Trujillo D, Majid A, Johnson MM, et al. Central Airway Collapse, an Underappreciated Cause of Respiratory Morbidity. Mayo Clin Proc 2020;95:2747-54.

2. Majid A, Kheir F, Alape D, et al. The Prevalence of Gastroesophageal Reflux in Patients With Excessive Central Airway Collapse. Chest 2019;155:540-5.

3. Gangadharan SP, Bakhos CT, Majid A, et al. Technical aspects and outcomes of tracheobronchoplasty for severe tracheobronchomalacia. Ann Thorac Surg 2011;91:157480; discussion 1580-1.

4. Shah V, Husta B, Mehta A, et al. Association Between Inhaled Corticosteroids and Tracheobronchomalacia. Chest 2020;157:1426-34.

5. Buitrago DH, Majid A, Alape DE, et al. SingleCenter Experience of Tracheobronchoplasty for Tracheobronchomalacia: Perioperative Outcomes. Ann Thorac Surg 2018;106:909-15.

6. Lazzaro R, Patton B, Lee P, et al. First series of minimally 
invasive, robot-assisted tracheobronchoplasty with mesh for severe tracheobronchomalacia. J Thorac Cardiovasc Surg 2019;157:791-800.

7. Clavien PA, Barkun J, de Oliveira ML, et al. The ClavienDindo classification of surgical complications: five-year experience. Ann Surg 2009;250:187-96.

8. Bezuidenhout AF, Boiselle PM, Heidinger BH, et al. Longitudinal Follow-up of Patients With Tracheobronchomalacia After Undergoing Tracheobronchoplasty: Computed Tomography Findings and Clinical Correlation. J Thorac Imaging 2019;34:278-83.

9. Ernst A, Odell DD, Michaud G, et al. Central airway stabilization for tracheobronchomalacia improves quality of life in patients with COPD. Chest 2011;140:1162-8.

10. Majid A, Alape D, Kheir F, et al. Short-Term Use of Uncovered Self-Expanding Metallic Airway Stents for

doi: $10.21037 /$ jovs-21-10

Cite this article as: Wilson JL, Wallace JS. Tracheobronchoplasty outcomes: a narrative review. J Vis Surg 2022;8:16.
Severe Expiratory Central Airway Collapse. Respiration Int Rev Thorac Dis 2016;92:389-96.

11. McGinn J, Herbert B, Maloney A, et al. Quality of life outcomes in tracheobronchomalacia surgery. J Thorac Dis 2020;12:6925-30.

12. Boiselle PM, Feller-Kopman D, Ashiku S, et al. Tracheobronchomalacia: evolving role of dynamic multislice helical CT. Radiol Clin North Am 2003;41:627-36.

13. Boiselle PM, O'Donnell CR, Loring SH, et al. Reproducibility of forced expiratory tracheal collapse: assessment with MDCT in healthy volunteers. Acad Radiol 2010;17:1186-9.

14. Buitrago DH, Wilson JL, Parikh M, et al. Current concepts in severe adult tracheobronchomalacia: evaluation and treatment. J Thorac Dis 2017;9:E57-66. 